\title{
Behavioural and social characteristics of the patient with repeated venereal disease and his effect on statistics on venereal diseases
}

\author{
R. S. LUNDIN, M. W. WRIGHT, AND J. N. SCATLIFF \\ From the Department of Psychiatry, Faculty of Medicine, University of Manitoba, Canada
}

SUMMARY The current study investigated personality characteristics and social circumstances in patients repeatedly infected with venereal diseases. An effort was made to identify characteristics that would differentiate a repeat patient (RP) from a non-repeat patient (NRP). Two studies were carried out. In the first, a group of patients from a venereal disease clinic in a large general hospital was first interviewed and then the patients were asked to complete a questionnaire. In the second study, an attempt was made to validate the findings from the first study by comparing data from RP and NRP venereal disease patients drawn from medical and social case histories from a second hospital. Results of both studies support the hypothesis that repeat patients are different from non-repeat venereal disease patients in terms of social and psychological characteristics. The significance of these findings is discussed.

\section{Introduction}

The rapid increase in reported cases of venereal disease during the last decade has prompted a multidisciplinary attack on epidemiological, socioeconomic, and psychological factors associated with the spread of venereal disease. Changes in values, attitudes, and moral behaviour, are frequently blamed as being the cause (Morton, 1973). However, it could be argued that the increase in venereal disease rates is a reflection of better reporting of cases treated in private practice, although surveys among private physicians have been poorly reported (Curtis, 1963; Fleming et al., 1970; Scatliff, 1974). It is not known whether more patients with venereal disease are now being treated, or if more people are becoming infected. A third possibility is that individuals in so called 'high risk groups' are having more infections than before-that is, not more patients but more infections. Statistical reports on venereal disease usually give numbers of cases treated annually and it is difficult to determine

This investigation was supported, in part, by Orders-in-Council No. $627 / 74$ and 887/75 from the Manitoba Department of Health and Social Development, Research Support Funds as project no. 002, Winnipeg, Manitoba, R3C OP8.

Address for reprints: Dr R. S. Lundin, Department of Psychology, University of Manitoba, Winnipeg, Canada R3T 2N2

Received for publication 5 March 1976 whether more individuals are being infected or if fewer individuals are being more frequently infected.

The current study is focused on patients with histories of repeated venereal infections. It is important to make a distinction between the repeat patient (RP) and the non-repeat patient (NRP), as in addition to the above-mentioned statistical problems, it is possible that RPs differ from NRPs in respect to life styles, personality characteristics, and environmental circumstances. Such differences could have important implications in understanding and treating patients. It is also possible that such information could be used to construct a method to identify potential repeaters.

The current study comprises two investigations. The first assessed patients in a hospital clinic; the second reviewed a large number of medical records drawn from a second hospital to check on the findings of the first study.

\section{First study}

METHOD

Eighty-two subjects drawn from patients attending St Boniface General Hospital in Winnipeg, Canada, participated in this study. Table 1 shows demographic characteristics of the experimental group (RP) and the control group (NRP). Patients were divided into two groups according to the frequency of venereal infections during a two-year period, 
NRP having one reported infection and RP having four or more infections during that time. The possibility of a difference owing to cultural background in Canada's native population (Indians) versus white Canadians was controlled by having an almost equal number of natives and whites in both groups (RP, 20 natives/21 whites; NRP 18 natives/23 whites).

\section{PROCEDURE}

Patients having four or more venereal infections during a two-year period (RP) (as indicated by their charts) were selected first $(\mathrm{N}=41)$. Patients with only one infection during the same period (NRP, $\mathrm{N}=41$ ) were used as controls. The subjects were asked to participate voluntarily during contacttracing interviews. Eighty-eight patients were approached and six declined to take part. Data were obtained during confidential interviews, at which questionnaires, trait, and attitude scales were administered. Interview questions were designed to evaluate social values, living conditions, and personality characteristics. The questionnaire was made up of thirteen items measuring quantifiable personality traits as developed by Lindgren (1969). Each answer was measured on a seven-point scale according to the magnitude of the respective trait within a range from absent $(0)$ to highly represented (7). The subjects were asked to mark with a pencil their own position on the scale. The data were divided into three main categories: biographical variables, neighbourhood factors, and scaled data. Biographical data were obtained partly from interviews and partly from patient files. This information was later used to obtain scores on Hollingshead and Redlich (1958) 'two factor index of social position'. Similarly, neighbourhood data were obtained from medical records and by questions. Coloured ink was used to plot each patient's address on a map of the city of Winnipeg. Areas which showed clustering of RPs were encircled, making it possible to compare the concentration of RP and NRP for any area of the city. All tests for statistical significance were made using $\chi^{2}$ with Yates's correction (Yates, 1934). Qualitative data were obtained from self-reported case histories and non-quantifiable responses to items in the questionnaire.

\section{Results}

Table 1 summarises the findings on biographical data, location of home, and frequency of changes in address for the two groups. The educational level of the NRPs was higher than that of the RP group by roughly three years of schooling, this difference being statistically significant $\left(\chi_{1}{ }^{2},=6.3, P<0.05\right)$. Scores on 'two factor index of social position' (Hollingshead and Redlich, 1958) indicated the lowest socioeconomic level for both groups. The RPs were mobile during the observed period, but the NRPs were relatively stable and changed their addresses less frequently. The difference between the two groups was significant $\left(\chi_{2}{ }^{2}=10.90, \quad \mathrm{P}<0.001\right)$. Table 1 shows the percentage of subjects residing within the few city blocks comprising the two cluster areas. As indicated $92 \%$ of the RPs lived within the cluster area, whereas only $18 \%$ of the NRPs had addresses in the same locality. This difference is significant $\left(\chi_{2}{ }^{2}=12 \cdot 25, \mathrm{P}<0.001\right)$.

Scaled data (Mean ratings on seven-point scales) Table 2 shows significant statistical differences between the RP group and the NRP group $\left(\chi_{2}{ }^{2}=\right.$ $12.76, \mathrm{P}<0.001)$ in their relationships. The higher scores for NRPs (5.7 versus 1.5 for RPs) represents longer lasting relationships, with a presumed greater degree of personal commitment. The NRPs

Table 2 Measures of personality characteristics and attitudes* in RP compared with NRP

\begin{tabular}{lllrl}
\hline Characteristic & $R P$ & $N R P$ & $\chi_{2}{ }^{2}$ & \multicolumn{1}{c}{$P$} \\
\hline Personal relationships & 1.5 & 5.7 & 2.76 & $<0.05$ \\
Self-esteem & 2.8 & 5.3 & 10.43 & $<0.01$ \\
Attitude towards society & 3.0 & 5.8 & 12.32 & $<0.001$ \\
\hline
\end{tabular}

*(Adapted from Lindgren, 1969)

tended to have higher scores on self-esteem, as measured, than had RPs $(5 \cdot 8$ for NRP versus $2 \cdot 8$ for RP, $\left.\chi_{2}{ }^{2}=10.43, P<0.01\right)$. Scales measuring attitudes toward society (Lindgren, 1969) on a continuum from 'destructive' (0) through 'absent' (3) to 'highly constructive' (7) indicated significantly higher scores for NRPs $(5 \cdot 8)$ than the corresponding scores for RPs $(3.0),\left(\chi_{2}^{2}=12.32, P<0.001\right)$.

Table 1 Biographical data, educational level, and mobility scores for repeat venereal disease patients (RP) compared with non-repeat patients (NRP)

\begin{tabular}{|c|c|c|c|c|c|c|c|c|c|c|}
\hline \multirow[b]{2}{*}{ Group } & \multirow[b]{2}{*}{$\begin{array}{l}\text { Men } \\
\text { (no.) }\end{array}$} & \multirow[b]{2}{*}{$\begin{array}{l}\text { Women } \\
\text { (no.) }\end{array}$} & \multirow[b]{2}{*}{$\begin{array}{l}\text { Age } \\
\text { (mean) }\end{array}$} & \multirow[b]{2}{*}{$\begin{array}{l}\text { Education } \\
\text { (years at school) }\end{array}$} & \multirow[b]{2}{*}{$\begin{array}{l}\text { Social } \\
\text { class }\end{array}$} & \multicolumn{3}{|c|}{ Marital state } & \multirow[b]{2}{*}{$\begin{array}{l}\text { Address change } \\
\text { in } 3 \text { months (mean) }\end{array}$} & \multirow[b]{2}{*}{$\begin{array}{l}\text { Percentage living } \\
\text { within clusters }\end{array}$} \\
\hline & & & & & & $\begin{array}{l}\text { Married } \\
\%\end{array}$ & $\begin{array}{l}\text { Cohabiter } \\
\%\end{array}$ & $\begin{array}{l}\text { Single } \\
\%\end{array}$ & & \\
\hline $\begin{array}{l}\text { RP } \\
\text { NRP }\end{array}$ & $\begin{array}{l}23 \\
19\end{array}$ & $\begin{array}{l}18 \\
22\end{array}$ & $\begin{array}{r}25: 5 \\
23 \cdot 8\end{array}$ & $\begin{array}{l}6 \cdot 4 \\
9 \cdot 5\end{array}$ & $\begin{array}{l}\mathbf{V} \\
\mathbf{V}\end{array}$ & $\begin{array}{r}2 \\
24\end{array}$ & $\begin{array}{l}70 \\
20\end{array}$ & $\begin{array}{l}28 \\
56\end{array}$ & $\begin{array}{l}3 \cdot 1 \\
0 \cdot 7\end{array}$ & $\begin{array}{l}92 \\
18\end{array}$ \\
\hline
\end{tabular}


SUMMARY OF RESULTS

Patients with a history of repeated venereal infections (RP) differed significantly from patients with no such history (NRP) with respect to both environmental factors and personality characteristics. The RP group had more natives who were born and grew up on reserves than had the NRP group, whose native population tended to have grown up in the city. The low level of education for RPs compared with the better educated NRPs may be related to the limited educational opportunities offered to natives who grow up on reservations. Social position scores placed both groups in level five (lowest) in a fivelevel stratification index. The difference between RPs and NRPs was small but it should be noted that the NRP group was bordering on level four. This difference, although not statistically significant, may mean the difference between having a lowpaid job for NRPs as opposed to living on public welfare for RPs. It is also noted that the higher educational level for NRPs contributes to a higher classification on the social scale as the two factors used to determine social class are educational level and occupational role (Hollingshead and Redlich, 1958).

The reasons given by members of the RP group for their frequent changes in address were: difficulties in keeping up rent payments, conflicts with landlords, losing their jobs, or moving elsewhere to seek new employment.

\section{Second study}

To test validity of the findings of the first study a second investigation was undertaken.

\section{METHOD}

Data were gathered from medical records only, and these were obtained from the Provincial Department of Venereal Disease Control. Only records of patients treated at Winnipeg General Centre were used. Out of 500 records drawn in serial order, 280 files were deleted because they lacked sufficient information. An attempt to achieve equal numbers among the RP and NRP groups further reduced the number of records to $100 \mathrm{RP}$ and $100 \mathrm{NRP}$ charts. Any difference due to gender was controlled by randomly selecting males and females from both groups. Sex distribution was 26 RP men and 26 RP women, 24 NRP men and 24 NRP women. When testing for sex differences male RPs and NRPs were combined into one group and female RPs and NRPs into another. Presenting complaints upon admission to the clinic (as indicated in the charts) were tabulated for both groups over a three-year period. It was found that RPs had significantly more admissions than NRPs $(X=18$ for $R P$ versus 9 for NRP) this factor was controlled by dividing the frequency of a complaint, as it occurred in a group, by the frequency of admission. Hence, for alcoholism, which was mentioned in 150 admissions out of a total of $\mathbf{3 0 0}$ for the RP group, the percentage used was calculated as 50. Presenting complaints were tabulated under 13 variables for RPs and NRPs, and sex differences were measured for five of them (Fig. 2). These variables were selected arbitrarily by the authors as being most likely to reveal male-female differences.

\section{Results}

Further support for the notions of differences between RPs and NRPs as found in the first study was obtained in the second study. Figure 1 shows that the RP group had a higher proportion of admissions than had the NRP group with respect to alcohol problems $\left(\chi_{1}{ }^{2}=4.38, P<0.05\right)$; slightly fewer admissions for drug abuse other than alcohol (non-significant); significantly more injuries sustained in physical conflict $\left(\chi_{1}^{2}=8.32, P<0.01\right)$; a higher proportion of infectious disease other than venereal disease such as influenza, tuberculosis, infectious hepatitis, infected lacerations, etc. $\left(\chi_{1}{ }^{2}=\right.$ $12.20, P<0.001)$; psychiatric disorders $\left(\chi_{1}{ }^{2}=5.36\right.$, $P<0.05)$; and involvement with the police with resulting injuries $\left(\chi_{1}^{2}=3.85, \quad P<0.05\right)$; whereas women in the NRP group had slightly higher frequency of abortions and interrupted pregnancies (non-significant).

Figure 2 shows the differences between the sexes as well as those between RP and NRP groups. It shows that attempted suicides were nearly the same for RPs and NRPs, but that most suicide admissions were clearly accounted for by women $\left(\chi_{1}^{2}=7 \cdot 25\right.$, $P<0.01)$. RPs had a higher incidence of accidental injuries than had the NRP group $\left(\chi_{1}^{2}=3.97\right.$, $P<0.05$ ) but no significant sex difference was obtained on the same measure. Venereal infections through homosexual contacts were significantly higher for RPs than for NRPs $\left(\chi_{1}{ }^{2}=4.26, P<0.05\right)$ and were more frequent in men $\left(\chi_{1}^{2}=12.94, P<\right.$ $0.001)$. The NRP group had a higher incidence of hypochondriasis and psychosomatic complaints $\left(\chi_{1}{ }^{2}=3.86, \mathrm{P}<0.05\right)$ particularly for men $\left(\chi_{1}^{2}=5.98\right.$, $P<0.05$ ). More RPs came from broken homes than did NRPs $\left(\chi_{1}^{2}=7 \cdot 18, P<0.05\right)$ and more than twice as many women as men $(50 \%$ versus $18 \%)$ came from a disrupted family background $\left(\chi_{1}{ }^{2}=13 \cdot 75\right.$, $P<0.001$ ). 


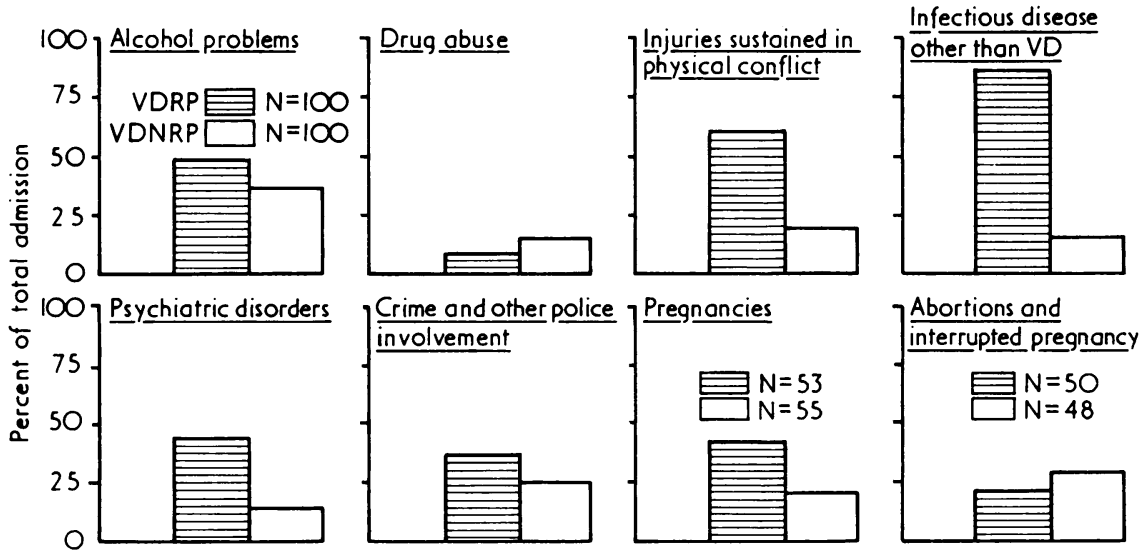

Fig. 1 Distribution of presenting symptoms of RP and NRP as percentage of total admissions to primary health care, Health Sciences Centre, Winnipeg

\section{Discussion}

It is evident that the RP and NRP groups vary both socially and psychologically. The RPs tend to live in circumscribed areas of the city and relationships are casual and of limited duration. The repeated pattern of venereal infections seems to reflect a way of life rather than a specific health problem, and the RP is more likely to suffer from medical problems. Further insight into the nature of the RP problem may be obtained by studying the contact person(s). In reviewing files of RPs treated it was found that of 206 files drawn at random, $83(40 \%)$ of the cases reported contacts which, when checked, also turned out to be repeaters. In other words, the RPs appears to be a self-perpetuating group, as reflected by geographical location and transmission of venereal disease contacts. The critical nature of this observation is related to the number of RPs found in the study and the statistical implications. From a sample of 500 charts drawn at random from hospital files, 220 were selected as only these had sufficient data to be accepted. It is thus important to acknowledge the fact that RPs would be more likely to have more hospital admissions, larger files, and therefore would be more likely to be included in the sample. However, it still seems reasonable to suppose that at the very least one-quarter of the total number of records came from the RP group. If we were accounting for infections alone, then, the RP group might represent approximately one-half of the infections. These differing statistics are cited to indicate the importance of differentiating between number of infections and number of patients infected, as the two statistics may be quite different and have different implications.

If the findings of this study can be generalised to other venereal disease populations, it is probable that RPs make up a sizeable proportion of venereal disease patients in the population at large. The
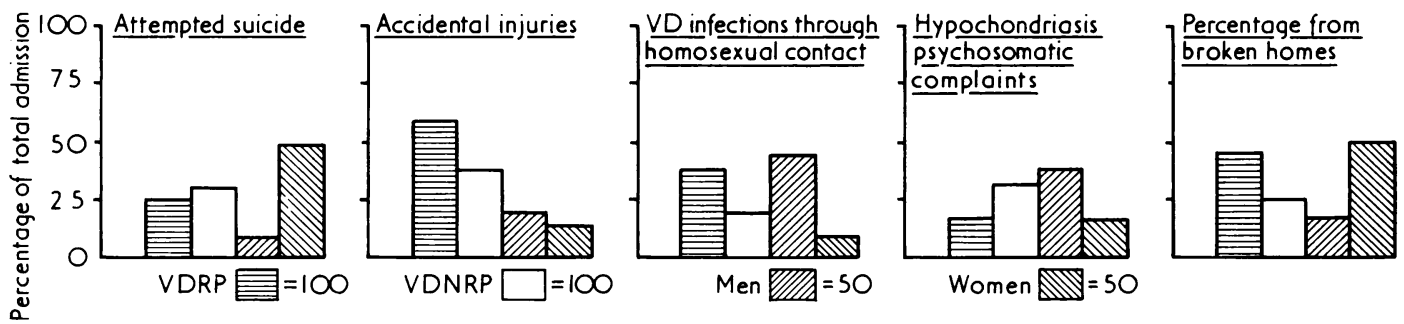

Fig. 2 Distribution of presenting symptoms of RP and NRP in men and women expressed as percentage of total admissions to primary health care, Health Sciences Centre, Winnipeg 
findings in these studies suggest that the repeater may require a different prophylactic treatment from the non-repeater.

We are currently working with groups of RPs to explore effective treatments.

\section{References}

Curtis, A. C. (1963). National survey of venereal disease treatment Journal of the American Medical Association, 186, 46-49.

Fleming, W. L., Brown, W. J., Donohue, J. F., and Branigin, P. W. (1970). National survey of venereal disease treated by physicians in 1968. Journal of the American Medical Association, 211, 18271830.
Hollingshead, A. B., and Redlich, F. C. (1958). Two factor index of social position. In Social Class and Mental Illness. Wiley: New York. Lindgren, H. C. (1969). Social motives, attitudes and their measurements. In Contemporary Research in Social Psychology. Wiley: New York.

Morton, R. S. (1973). Social indicators and venereal disease. British Journal of Venereal Diseases, 49, 155-156.

Scatliff, J. N. R. (1974). Survey of venereal disease treated by Manitoba physicians in 1972. Canadian Medical Association Journal, 110, 179-182.

Yates, F. (1934). Contingency tables involving small numbers and the $\chi^{2}$ test. Journal of the Royal Statistical Society, Supplement 7, 217-235. 